\title{
Paediatric crossword puzzle 21
}

\section{Manouri P Senanayake ${ }^{1}$}

Sri Lanka Journal of Child Health, 2013; 42: 227

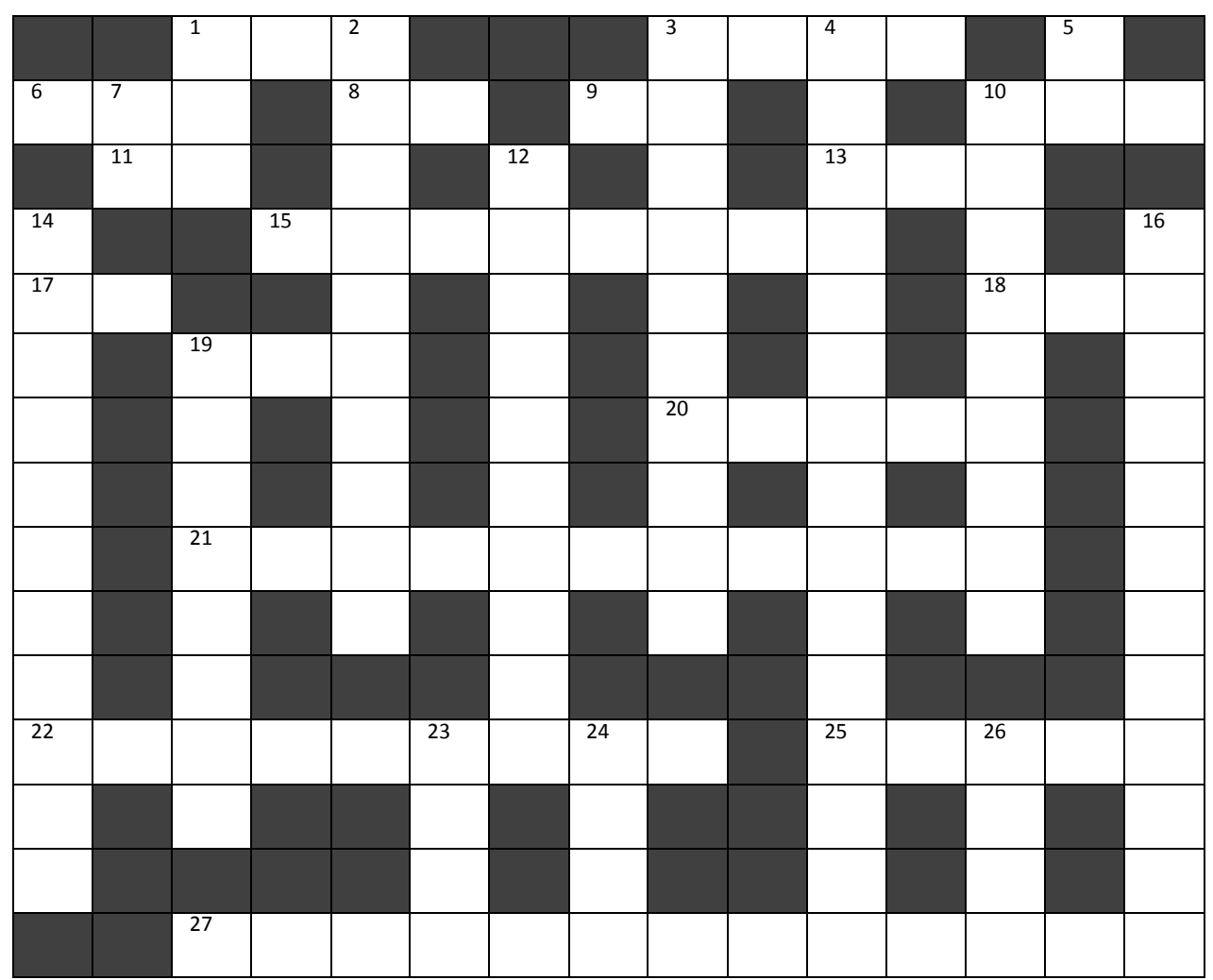

\section{Across}

1. newborn who chokes when fed

3. impulsivity, hyperactivity and poor attention

6 . tested when assessing growth hormone (abbrv.)

8. sun exposure inducing vitamin $\mathrm{D}$ production

9. metallic element in cell membranes

10. WHO standards for obesity

11. a measure of acidity

13. technique of amplifying copies of DNA (abbrv.)

15. a neurotransmitter

17. Koch's disease

18. intravenous infusion (abbrv.)

19. cessation of life

20. turns blue in methaemoglobinaemia

21. causes precipitous reduction in blood pressure

22. pertaining to the tonsil

25. fluorescent red dye used in histology

27. dyselectrolytaemia linked with hypophosphatemia

\section{Down}

1. an anterior pituitary secretion

2. a loop diuretic

3. a nephrotoxic drug commonly used in ICU

4. cause of isotonic hyponatraemia

5. best route for administration of adrenaline

7. comprehensive British document on medicinal substances (abbrv.)

10. cranial nerve palsies help localize lesion

12. shifts $\mathrm{K}+$ into cells

14. height measuring device

16. tumor causing Cushing's disease

19. pseudo-hypertrophy in calves

23. a cosmetic surgery requiring suction

24. auto-antibody in systemic vasculitis (abbrv.)

26. substandard housing

\section{${ }^{1}$ Professor in Paediatrics, Faculty of Medicine, University of Colombo}

